\title{
A EFICÁCIA DOS DIREITOS FUNDAMENTAIS E A IRRADIAÇÃO DOS PRINCÍPIOS CONSTITUCIONAIS SOBRE O DIREITO CIVIL
}

Kennedy Bispo Silva Conceição*

Saul Duarte Tibaldi**

\begin{tabular}{l|l}
\hline RECEBIDO EM: & 29.7 .2020 \\
\hline APROVADO EM: & $1^{\circ} .11 .2020$ \\
\hline
\end{tabular}

* Pesq

uisador do Grupo de Direito ao Trabalho Contemporâneo. Contabilista. E-mail: kennedybispo29@gmail.com Professor adjunto de Direito do Trabalho e Processo do Trabalho na graduação e pós-graduação da Universidade Federal de Mato Grosso (UFMT). E-mail: sauldt@ig.com.br 
- Resumo: Diante da tensão entre a possibilidade ou não de se fazer a leitura dos institutos do direito privado numa perspectiva constitucional, mediante a irradiação dos princípios constitucionais, este estudo procura respostas possíveis dentro da teoria dos direitos fundamentais. Para isso, será feito um levantamento teórico dos principais conceitos de direito fundamental, norma, ordenamento e princípio, para assim ser possível identificar chaves de leituras capazes de harmonizar, dentro da teoria constitucional, o diálogo entre os ordenamentos. Desde já reconhecendo que, se, por um lado, é impossível negar a imperatividade das normas constitucionais, frustra, por outro, o interesse constitucional na aplicação irrestrita dos seus princípios. Assim, o artigo buscará um meio-termo capaz de responder a essas questões.

- Palavras-chave: Direitos fundamentais; direito constitucional; direito privado; institutos; princípios.

\section{THE EFFECTIVENESS OF FUNDAMENTAL RIGHTS AND THE} IRRADIATION OF CONSTITUTIONAL PRINCIPLES ON CIVIL LAW

- ABSTRACT: Facing the tension between the possibility or not of reading the private law institutes in a constitutional perspective, through the irradiation of constitutional principles, this study looks for possible answers within the theory of fundamental rights. For this, a theoretical survey of the main concepts of fundamental law, rule, order and principle will be made, so that it is possible to identify keys of readings capable of harmonizing, within the constitutional theory, the dialogue between the orders. Already recognizing that, if, on the one hand, it neglects to deny the imperative of constitutional rules, on the other, the constitutional interest frustrates the unrestricted application of its principles. Thus, the article will seek a middle ground capable of answering these questions.

- KEYwords: Fundamental rights; constitutional right; private right; institutes; principles. 


\section{Introdução}

$\mathrm{Na}$ evolução do direito brasileiro, as contradições presentes no contexto social da criação das normas jurídicas não foram consideradas em benefício dos desabonados. Com a superveniência da Constituição Cidadã em 1988, a jurisdição constitucional se aprimorou cada vez mais para efetivar os direitos fundamentais ora positivados. Nos embargos previstos desse processo, estava a questão da divisão entre o espaço público e o privado.

O aprimoramento teórico contemporâneo permitiu desvencilhar a divisão unívoca do direito, de modo que a tendência da ciência jurídica atualmente é a complementaridade. Afora as hoje pequenas resistências possíveis aos raios constitucionais no direito privado, a discussão gira em torno do grau e modo como se dá a interferência dos princípios e direitos fundamentais na relação entre os particulares, de maneira mais afeta, no campo do ordenamento civil.

O presente trabalho é uma soma aos debates que procurará fazer uma digressão teórica acerca dos elementos presentes nessa discussão contemporânea, a saber, a questão da norma de direito fundamental e sua estrutura, os ordenamentos, a hermenêutica constitucional e a divisão entre o público e o privado, e sua tendência à complementaridade, procurando, assim, oferecer um consenso possível entre as teorias existentes. Para isso, este trabalho se valerá do método hipotético-dedutivo por meio da pesquisa bibliográfica.

\section{A norma de direito fundamental no ordenamento}

É fundamental de pronto admitir que não há, dentro da ciência jurídica, um conceito pacífico para o que seja a norma jurídica, o direito ou até mesmo o ordenamento. “Max Ernest Mayer escreve que ainda não tem havido um jurista ou jusfilósofo que tenha conseguido formular um conceito de direito, unanimemente aceito" (DINIZ, 2019 , p. 19), de modo que as formulações que venham a ser trabalhadas aqui possam ser encaradas como uma das possibilidades dentro das muitas respostas dotadas de igual competência.

Dentro de uma primeira concepção positiva, o direito pode ser concebido como um bem jurídico que se encontra em um ou mais enunciado normativo (ALEXY, 2006) 
que é determinado mediante a norma. Nessa primeira parte da conceituação, está a se diferenciar o conceito de norma como produto da atividade hermenêutica, ou seja, a norma não se encontra posta, mas é reproduzida, não produzida (GRAU, 2009), mediante a operação interpretativa do intérprete autêntico (KELSEN, 2006).

Reproduzida porque, como ensina Grau (2009, p. 472), o direito é alográfico, ou seja, sua realização requer a dualidade autor-intérprete para que se complete, de modo que "a completude do texto somente é atingida quando o sentido por ele expressado é produzido, como nova forma de expressão, pelo intérprete”, desse modo é na atividade hermenêutica que se firmam as qualidades jurídicas a um determinado enunciado normativo. Isso significa dizer que os bens jurídicos terão suas urgências de tutelas definidas mediante a capacidade de interpretação do jurista.

Nessa esteira, os enunciados de direitos fundamentais presentes na Constituição têm sua tutela disposta a cargo da hermenêutica capaz de dar-lhes tutela efetiva. Écerto que há o rol daqueles que são tidos como invioláveis, porém, no concurso da atividade jurisdicional, não raro e como costumeiro, verifica-se o reconhecimento de novos enunciados constitucionais com o status de direito fundamental. Isso ocorre porque, nos direitos fundamentais, em razão de sua natureza exigir a maior prestação jurisdicional dentro das possibilidades fáticas jurídicas (ALEXY, 2006) existentes, sua tutela se dá dentro da unidade funcional com o ordenamento.

O ordenamento, por sua vez, contempla a unidade dos enunciados normativos (BOBBIO, 2014) de um determinado sistema jurídico (CRETELLA JR., 1993). As noções clássicas de ordenamento jurídico, se investigadas a fundo - o que não poderá ser feito na ocasião -, levarão à noção de sistema piramidal kelseniano, em que, quando se olha de cima para baixo, há uma relação de complementaridade entre as normas, em que as normas superiores, quando formais, determinam como devem ser criadas as inferiores e, quando materiais, delimitam os conteúdos possíveis de serem abarcados pelas normas inferiores, numa relação de simetria de obrigações (BOBBIO, 2014).

A definição de direito fundamental, a seu turno, no ordenamento pátrio pode ser verificada em sentido estrito ou em sentido amplo. Em sentido estrito quando isolada em um único enunciado normativo. Em sentido amplo quando analisada e extraída de dois ou mais enunciados normativos (ALEXY, 2006). Didaticamente, é possível falar do direito à propriedade.

A Constituição de 1988, em seu art. $5^{\circ}$, XXII, assegura o direito à propriedade, o que por si só é garantido como um direito fundamental em sentido estrito, porém, 
acrescido ao inciso XXIII, com a dicção da função social da propriedade, há a formulação do direito de propriedade em sentido amplo, garantido pela Constituição, desde que atenda à sua função social.

Desse modo, a norma de direito fundamental requer sempre uma leitura funcional. Os sentidos dos seus enunciados não se encerram naquilo que foi impresso pelo legislador. $\mathrm{O}$ ato de vontade presente da criação legislativa não deve viciar a interpretação, que deve buscar a complementaridade do texto com o ordenamento, de modo a perseguir a unidade das normas constitucionais, pois todas as normas, como ensinam Canotilho e Moreira (1993), possuem vida útil no ordenamento.

\subsection{O princípio e sua imperatividade}

Dentro da estrutura das normas de direito fundamental encontra-se então uma das mais profícuas fontes de debates do mundo jurídico: regras e princípios. Sabe-se que regras e princípios são normas (ALEXY, 2006), porém estes são conteúdos recentes na discussão da jusfilosofia, e, por sê-lo, sua aplicação também paira sobre grandes incertezas. Pode-se dizer que o tema dos "princípios ingressou - com grande clamor - na discussão filosóficojurídica em 1967, por mérito (ou culpa) de Ronald Dworkin” (GUSTINI apud ÁVILA, 2016, p. 14).

As normas dizem que algo que é deve ser de determinada maneira, e os princípios, da mesma forma, também dizem que algo deve ser; portanto, ambos são normas, e essa discussão foi superada em Alexy (2006). Porém, a forma de resolução de conflito - ou colisão para Alexy (2006) - entre os princípios é até hoje o impasse na teoria da decisão; no entanto, não caberá aqui tratar dessa questão. A ligação entre os princípios constitucionais e os direitos fundamentais está relacionada à forma como se deu a categorização deles.

As chamadas gerações de direitos fundamentais assimilaram as conquistas dos direitos aos princípios constitutivos, e os direitos de primeira geração, compreendidos como os civis e políticos, acentuariam o princípio da liberdade; os de segunda geração, econômicos sociais e culturais, otimizariam o princípio da igualdade; já os de terceira geração, denominados de titularidade coletiva ou difusa, promoveriam o princípio da solidariedade.

Há uma dificuldade no trato dos direitos fundamentais dentro dessa perspectiva "geracional” que vai além da sua denominação. Muito embora tenha ocorrido a tenta- 
tiva de a doutrina substituir “gerações” por “dimensões” (SARLET; MARINONI; MITIDIERO, 2017), o problema de associação dos princípios às fases europeias de conquistas dos direitos fundamentais não se resolve. Como lembra Mazzuoli (2014, p. 37-38),

No plano interno, por exemplo, a consagração nas Constituições dos direitos sociais foi, em geral, posterior à dos direitos civis e políticos, ao passo que no plano internacional o surgimento da Organização Internacional do Trabalho, em 1919, propiciou a elaboração de diversas convenções regulamentando os direitos sociais dos trabalhadores, antes mesmo da internacionalização dos direitos civis e políticos no plano externo.

Ainda, para além desse aspecto, se os direitos fundamentais de primeira geração são assimilados aos direitos de liberdades, isso significaria dizer que sua tutela e prestação jurisdicional poderiam se dar por via individual como direito público subjetivo (HACHEM, 2019); já os direitos de terceira geração, assimilados ao princípio da solidariedade, apenas teriam sua prestação jurisdicional colmatada mediante ação coletiva, uma vez que não se configuraria como direito público subjetivo (HACHEM, 2019), limitando assim sua tutela.

Os direitos fundamentais de primeira, segunda ou terceira geração, associados a quaisquer princípios constitucionais têm características comuns que os dotam de imperatividade ao 1 . dirigirem deveres de abstenção ao poder público, 2. imporem ao Estado obrigações de prover prestações fáticas e normativas, e 3. possuírem, ao mesmo tempo, tanto a titularidade transindividual supostamente exclusiva dos "direitos de terceira geração" quanto a titularidade individual alegadamente típica dos “direitos de primeira e segunda gerações” (HACHEM, 2019). Por essa razão, será abandonada a associação dos direitos fundamentais a princípios constitucionais, pois, uma vez isso feito, é limitada a tutela dos bens jurídicos por eles assegurados.

Feitas as primeiras considerações, é possível falar sobre o tratamento constitucional aos princípios e sobre a normatividade que lhes fora atribuída. Primeiramente, tem-se o princípio da dignidade humana, no qual se funda parte considerável dos ordenamentos democráticos. Há quem diga que cada direito fundamental representa uma parcela desse princípio (MOLINA, 2013), que, por sua vez, é, em sua natureza nuclear, a síntese da máxima kantiana, segundo a qual cada ser humano é um fim em si mesmo (BARROSO, 2015), não devendo, portanto, ser utilizado como meio para fins alheios ou metas coletivas. 
Nos ordenamentos democráticos, e assim é no Brasil, o princípio da dignidade humana passou a ser considerado um mínimo de justiça (BARROSO, 2015), segundo o qual as ordenações deveriam se balizar. No entanto, a imperatividade desse princípio, que é considerado preferencial entre os positivados, também é balanceada, pois, como leciona Molina (2013, p. 76), prelecionando Sarlet, “é nesse sentido que não podemos deixar de relembrar - na esteira de Alexy - que até mesmo o princípio da dignidade da pessoa humana [...] acaba por sujeitar-se, sendo contraposto à igual dignidade de terceiros, a uma necessidade de relativização".

Ainda nesse sentido, vale citar que é reconhecida na jurisprudência do Supremo Tribunal Federal (STF), há razoável tempo, essa necessidade de harmonização dos princípios constitucionais às exigências de cada caso, a exemplo do julgado da lavra do ministro Celso de Mello, o Mandado de Segurança (MS) n. 23.452, de 16 de setembro de 1999, Tribunal Pleno, com o seguinte entendimento:

\footnotetext{
Não há, no sistema constitucional brasileiro, direitos ou garantias que se revistam de caráter absoluto, mesmo porque razões de relevante interesse público ou exigências derivadas do princípio de convivência das liberdades legitimam, ainda que excepcionalmente, a adoção, por parte dos órgãos estatais, de medidas restritivas das prerrogativas individuais ou coletivas, desde que respeitados os termos estabelecidos pela própria Constituição.
}

Com isso, hoje se reconhece que, na análise principiológica, não se admite mais a imperatividade absoluta e desmedida dos princípios, sendo necessária, na atividade hermenêutica, a extração de sentidos que o ordenamento procurou conferir àquele princípio à luz do caso in concreto, pois a justeza é perseguida na unidade funcional (CANOTILHO; MOREIRA, 1993) já presente nos textos normativos, sendo a norma o produto da interpretação e o princípio, uma norma fixada em uma regra, nunca uma realidade distinta do ordenamento, que, se assim o fosse, seria discricionariedade ilegítima.

\section{A chave de leitura da Constituição}

As normas de direito fundamental e as determinações principiológicas estão interligadas à eficácia das diretivas constitucionais. A Constituição, no que lhe concerne, por muito tempo - na dogmática constitucional - teve sua importância minorada, se 
comparada à supremacia que hodiernamente suas normas gozam. Ao sociologismo de Lassalle, o texto constitucional tinha unicamente a função de estabelecer diretrizes políticas que não logravam normatividade (HESSE, 1991). Essa ideia, presente na obra de Hesse (1991), muito embora pareça um absurdo aparente, não era uma realidade distante da prática na leitura das disposições constitucionais.

Por décadas, a Constituição desempenhou papel relativamente pequeno no direito doméstico, na incapacidade de produção de jurisprudência dos tribunais superiores em dotar de imperatividade as normas constitucionais. Mesmo "a doutrina, sobretudo europeia, especulou ao longo do tempo acerca da natureza, significação e papel da Constituição, produzindo elaborações diversas” (BARROSO, 2015, p. 144), sem, contudo, produzir a tempo da década de 1980, quando da constituinte, uma efetiva teoria constitucional que pudesse ser incorporada no território nacional.

Muito embora dentro da concepção conceitual positiva já houvesse a ideia de que formalmente a Constituição, na estrutura do ordenamento piramidal, encontrava-se no topo, donde havia de se dar o fundamento de validade das normas (KELSEN, 2006), no plano jurídico/político isso não era uma realidade.

Afirma-se não ser realidade não pela sua inexistência, porém por estar ausente. O ordenamento constitucional existia na realidade brasileira desde a Carta de 1824, quando da primeira tentativa frustrada de instituir uma certa formalidade entre a relação do privado com o público (BARROSO, 2015). No entanto, é apenas - e isso não se nega - com a constituinte de 1987/1988 que há a efetiva criação de um ordenamento constitucional capaz de impor-se como realidade normativa cogente que se vinculasse a todos, e, de tal sorte que, as instituições e os institutos existentes passaram a se moldar aos novos critérios constitucionais.

Muito embora possa, num primeiro momento, esse parecer ser um discurso romântico a respeito do Texto de 1988, há que se verificar que, malgrado o déficit do processo, os ganhos nos mecanismos de controles foram uma das principais conquistas que vieram garantindo a maior efetividade das normas constitucionais. Reconhecendo que foi adotado o sistema misto de controle de constitucionalidade e "agregando a ação de inconstitucionalidade por omissão, inspirado no constitucionalismo português e iugoslavo, a [...] arguição de descumprimento de preceito fundamental - ADPF e a ação declaratória de constitucionalidade - ADC, introduzida pela EC 3" (STRECK, 2018, p. 183), serviram, sobremaneira, para garantir o direito na função contramajoritária no sistema democrático. 
Hoje, portanto, sabe-se que a Constituição vincula que seus institutos são dotados de imperatividade e todas as suas normas possuem utilidade no ordenamento. Os mecanismos de controle inaugurados em 1988, aperfeiçoados na jurisdição constitucional, mediante a Emenda n. 45/2004, em sistema misto garantem a efetivação das disposições constitucionais. Resta saber quais foram, por ocasião da nova Constituição, as principais chaves - se elas existem - de interpretação dos demais ramos do direito, uma vez que se reconhece que é indissociável a leitura dos institutos em seu compromisso para com as finalidades constitucionais.

O direito existe gravitando em torno da justiça e da segurança (BARROSO, 2015), de modo que a Constituição procurou dar tratamento constitucional adequado à justiça assegurando, em primeiro plano, no título II, os direitos e as garantias fundamentais, dentre os quais, como trabalhado anteriormente, a dignidade humana, que foi posta no centro do ordenamento jurídico para irradiar as tutelas efetivas de proteção, e, ao seu lado, de modo reflexo à sua proteção, a segurança foi garantida ao positivar as liberdades e preservar o direito adquirido, o ato jurídico perfeito e a coisa julgada, no inciso XXXVI, art. $5^{\circ}$.

Em segundo plano, tem-se a proteção do princípio democrático, segundo o qual as principais mutações sociais devem se dar pela participação social na coisa pública. A instituição do Estado democrático no art. $1^{\circ}$ da Constituição requer que a promoção das transformações seja feita por meio da efetiva realização democrática, o que significa dizer que o Judiciário não pode substituir, por meio de tutela, as reivindicações que legitimamente devem ocorrer quando da omissão do poder público, salvo em se tratando de questões relacionadas a agressões aos direitos fundamentais, princípios e fins públicos sensíveis às maiorias políticas (BARROSO, 2015).

Em terceiro e, por fim, porém não exaustivo - sendo possíveis outras definições -, tem-se a proteção do princípio da igualdade, no qual os cidadãos gozam de iguais condições da vida pública $\left(\operatorname{art.} 5^{\circ}\right)$ para que possam desenvolver seu ofício $\left(\operatorname{art.} 7^{\circ}, \mathrm{XXX}\right)$ e, na vida política, tenham o mesmo valor em suas escolhas (art. 14), de modo que esse direito fundamental em sentido amplo seja critério balizador nas decisões políticas e judiciais. Considerando, contudo, a necessidade de se prever a discriminação positiva, uma vez que é direito implícito no texto constitucional, a fim de realizar a igualdade efetiva, a necessidade de desigualar os desiguais na medida de sua desigualdade e na promoção de políticas públicas. 


\subsection{A Constituição de 1988 e o direito privado}

A Constituição de 1988, como se verificou, chegou, e, com ela, suas normas e princípios, dotados pelos mecanismos de controle, passaram a vincular todo o sistema jurídico interno. As normas domésticas existentes passaram pelas disposições transitórias. As definições que foram recepcionadas continuaram a surtir efeito, e as que não, expurgadas do ordenamento. Porém, aliado ao fenômeno da constituinte, um elemento estava presente.

O movimento constitucionalista e as crescentes teorias no âmbito da jusfilosofia que afirmaram a força normativa da Constituição garantiram que o novo texto, diferentemente dos antecedentes, não iria mais ser deixado à baila como instrumento facultativo em que se prestigiavam mais, inegavelmente, o Código Civil e o Código Comercial. O direito constitucional surge então e firma-se como direito público(BARROSO, 2015), porém não alheio ao direito privado, pois suas normas abarcaram os elementos de todos os diplomas normativos.

A dicotomia entre direito público e privado, muito embora até hoje trabalhada pela doutrina, já não faz mais sentido em leitura rígida, uma vez que a tendência do direito é a complementaridade (REALE, 2002). Por regra, ao direito privado se compreende o predomínio da autonomia da vontade, em que a vontade faz norma entre as partes (DINIZ, 2019), e, por certo, “essas relações jurídicas dependem do consenso entre as partes. [...] a responsabilidade civil, como regra, é subjetiva. Violado um direito na esfera privada, seu titular tem a faculdade de defendê-lo" (BARROSO, 2015, p. 106).

Já em relação à coisa pública, o tratamento se dá no âmbito do direito público, no qual não vigora - ou pelo menos não deveria - a autonomia da vontade nas decisões dos agentes capazes das decisões: "O regime jurídico de direito público funda-se na soberania estatal, no princípio da legalidade e na supremacia do interesse público. A autoridade pública só pode adotar, legitimamente, as condutas determinadas ou autorizadas pela ordem jurídica” (BARROSO, 2015, p. 106).

O âmbito de atuação do direito constitucional, como direito público, torna-se maior na medida em que suas normas dizem respeito não só à matéria de prestação de direitos fundamentais de natureza coletiva, mas também aos mandamentos de caráter individual que requerem do Estado prestações fáticas e normativas. A Constituição de 1988 passou a dar tratamento constitucional a matérias diversas, de modo que muito do que era questão de direito privado passou a ter regramento constitucional. 
A questão da propriedade art. $5^{\circ}$, inciso XXI, porém devendo ter seu fim social atendido art. $5^{\circ}$ inciso XXII. Desapropriação de imóvel art. $5^{\circ}$, inciso XXIV. Direito de família tratado no art. 226, sendo a questão do casamento homoafetivo tratado em sede de ação direta de inconstitucionalidade (ADI) n. 4.277 (inicialmente ADPF 132) que requereu a interpretação conforme a Constituição do art. 1.723 do Código Civil. Tratou também de demandar em norma de eficácia limitada (SILVA, 1998), no art. $5^{\circ}$, inciso XXXII, sobre a defesa do consumidor e os direitos da criança e do adolescente art. 227.

Analiticamente, portanto, a Constituição de 1988 ao tratar de tantas matérias, que em outros países é competência da legislação infraconstitucional, fez com que fosse impossível interpretar qualquer instituto relevante sem que tocasse na questão constitucional que ele traz. Porém, dentro dessa mesma linha de raciocínio, é possível verificar que os códigos de legislação especial foram trabalhados, após o novo texto constitucional, à luz dos princípios e das regras gerais esposados na Constituição.

A exemplo disso, cita-se a Lei n. 8.069/90, o Estatuto da Criança e do Adolescente. Tal legislação prevê satisfatoriamente a proteção que o constituinte procurou prover ao estabelecer no art. 227, $\$ 4$, que “a lei punirá severamente o abuso, a violência e a exploração sexual da criança e do adolescente”. Dessa forma, essa legislação e outras recepcionadas pelo texto constitucional procuraram dar mais ênfase às normas e aos princípios lá identificados.

\section{A eficácia horizontal dos direitos fundamentais}

Como verificado, já não há mais claramente a divisão estanque entre o público e o privado, e lembra Molina (2013) que mesmo na Grécia não havia essa divisão na medida em que a política, os julgamentos e a elaboração das leis eram todos realizados na ágora. O tema da eficácia horizontal dos direitos fundamentais procura saber se os princípios e as normas constitucionais possuem eficácia apenas em face do Estado ou, como defendem os adeptos (TARTUCE, 2019), se também logram efetividade imediata nas relações entre particulares.

Não há dúvidas de que os direitos fundamentais contêm normas que vinculam o poder público e que requerem uma prestação negativa por parte do Estado (HACHEM, 2019), no sentido de autocontenção, porém não se limita a atividade estatal às agressões a 
determinado bem jurídico, por isso a incidência dos direitos fundamentais em alguma medida na relação entre os particulares não se nega. Há, em algum grau, entre iguais, no âmbito do direito privado, a eficácia dos direitos fundamentais.

No entanto, isso já é reconhecido pela doutrina, de modo que, verificada essa mudança valorativa, o questionamento é sobre o grau e o modo como se dá a aplicação dos direitos fundamentais nas relações privadas. Há os que comungam da tese de que a eficácia deva ser "indireta e aplicabilidade mediata, por meio da atuação legislativa" (BARROSO, 2015, p. 603), ou seja, o legislador, por meio da edição de leis, deve promover a incorporação das normas constitucionais nas legislações especiais, já que não teria o juiz, na aplicação do caso in concreto, "legitimidade popular para delimitar o nível de aplicação de um direito fundamental” (MOLINA, 2013, p. 114).

Há, no entanto, os que partilham a tese de que a eficácia seja direta com aplicação imediata "mediante um critério de ponderação entre os princípios constitucionais da livre iniciativa e da autonomia da vontade, de um lado, e o direito fundamental em jogo, do outro lado" (BARROSO, 2015, p. 603-604). Essa tese é adotada e justificada na necessidade perene, na realidade brasileira, de uma maior intervenção social, perquirindo de garantir justiça social por meio dos direitos fundamentais. Os que essa tese defendem o fazem no sentido de dizer que, se o legislador não promove as garantias que a Constituição positivou, seja incumbido o julgador de fazê-lo (MOLINA, 2013).

No STF, sob a relatoria do ministro Gilmar Mendes, no Recurso Extraordinário (RE) n. 201.819-8/RJ' ${ }^{1}$, foi adotada última a tese, segundo a qual os direitos fundamen-

1 EMENTA: SOCIEDADE CIVIL SEM FINS LUCRATIVOS. UNIÃO BRASILEIRA DE COMPOSITORES. EXCLUSÃO DE SÓCIO SEM GARANTIA DA AMPLA DEFESA E DO CONTRADITÓRIO. EFICÁCIA DOS DIREITOS FUNDAMENTAIS NAS RELAÇÕES PRIVADAS. RECURSO DESPROVIDO. I. EFICÁCIA DOS DIREITOS FUNDAMENTAIS NAS RELAÇÕES PRIVADAS. As violações a direitos fundamentais não ocorrem somente no âmbito das relações entre o cidadão e o Estado, mas igualmente nas relações travadas entre pessoas físicas e jurídicas de direito privado. Assim, os direitos fundamentais assegurados pela Constituição vinculam diretamente não apenas os poderes públicos, estando direcionados também à proteção dos particulares em face dos poderes privados. II. OS PRINCÍPIOS CONSTITUCIONAIS COMO LIMITES À AUTONOMIA PRIVADA DAS ASSOCIAÇÕES. A ordem jurídico-constitucional brasileira não conferiu a qualquer associação civil a possibilidade de agir à revelia dos princípios inscritos nas leis e, em especial, dos postulados que têm por fundamento direto o próprio texto da Constituição da República, notadamente em tema de proteção às liberdades e garantias fundamentais. $\mathrm{O}$ espaço de autonomia privada garantido pela Constituição às associações não está imune à incidência dos princípios constitucionais que asseguram o respeito aos direitos fundamentais de seus associados. A autonomia privada, que encontra claras limitações de ordem jurídica, não pode ser exercida em detrimento ou com desrespeito aos direitos e garantias de terceiros, especialmente aqueles positivados em sede constitucional, pois a autonomia da vontade não confere aos particulares, no domínio de sua incidência e atuação, o poder de transgredir ou de ignorar as restrições postas e definidas pela própria Constituição, cuja eficácia e força normativa também se impõem, aos particulares, no âmbito de suas relações privadas, em tema de liberdades fundamentais [...]. STF - Segunda Turma - RE no 201.819-8/RJ - Rel. Min. Gilmar Mendes, 2005. 
tais esposados na Constituição têm sua aplicabilidade imediata nas relações privadas. Nesse caso específico, há que se registrar que, muito embora a eficácia direta tenha ocorrido, o ministro Joaquim Barbosa consignou a necessidade de que a incidência devesse ser verificada com parcimônia, caso a caso, para que não se inviabilizasse a esfera da autonomia privada dos indivíduos (MOLINA, 2013).

Não somente nessa ocasião o STF adotou a tese da eficácia horizontal dos direitos fundamentais sobre as relações entre privados, mas também quando impôs igualdade de tratamento aos funcionários não franceses da Air France, no REn. 161.243², julgado pela segunda turma na relatoria de Carlos Velloso, que recebiam tratamento diferenciado dos franceses, este de natureza antecedente àquele, prestigiando, assim, o princípio da igualdade ante a autonomia privada de as companhias áreas de definirem suas normativas internas.

\subsection{O direito civil constitucional}

O direito civil é, por excelência, o ramo do direito privado destinado a reger as relações familiares, patrimoniais e obrigacionais que se formam entre os indivíduos como membros de uma mesma sociedade (DINIZ, 2019), de modo que suas normas disciplinam como esses poderão contratar e, contratando, produzir normas válidas entre si. É o direito do cotidiano, a constituição do homem comum (REALE, 2002), que regula as atividades das mais simples às mais complexas. Étambém o direito da vida, que disciplina desde o nascimento, na parte geral, o direito dos nascituros e, ao morrer, o direito das sucessões, trabalhado em sua parte especial.

Como verificado anteriormente, é de sua natureza que os princípios privados valorizem os elementos do querer individual, sendo eles a autonomia da vontade, representada na capacidade de o indivíduo praticar os atos da vida civil, e a liberdade nego-

2 EMENTA: CONSTITUCIONAL. TRABALHO. PRINCÍPIO DA IGUALDADE. TRABALHADOR BRASILEIRO EMPREGADO DE EMPRESA ESTRANGEIRA: ESTATUTOS DO PESSOAL DESTA: APLICABILIDADE AO TRABALHADOR ESTRANGEIRO E AO TRABALHADOR BRASILEIRO. C.F., 1967, art. 153, § 10; C.F., 1988 , art. $5^{\circ}$, caput. I. - Ao recorrente, por não ser francês, não obstante trabalhar para a empresa francesa, no Brasil, não foi aplicado o Estatuto do Pessoal da Empresa, que concede vantagens aos empregados, cuja aplicabilidade seria restrita ao empregado de nacionalidade francesa. Ofensa ao princípio da igualdade: C.F., 1967, art. 153, $\$ 1^{\text {o}}$; C.F., 1988 , art. $5^{\circ}$, caput). II. - A discriminação que se baseia em atributo, qualidade, nota intrínseca ou extrínseca do indivíduo, como o sexo, a raça, a nacionalidade, o credo religioso, etc., é inconstitucional. Precedente do STF: Ag 110.846(AgRg) - PR, Célio Borja, RTJ 119/465. III. - Fatores que autorizariam a desigualização não ocorrentes no caso. IV. - R.E. conhecido e provido. STF - RE161243, Relator(a): Min. CARLOS VELLOSO, Segunda Turma, julgado em 29/10/1996. 
cial, possibilidade de se atribuir a ele direitos e de que este os aceite (DINIZ, 2019), de modo que as demais áreas do direito privado recorrem às normas do Código Civil para suprir eventuais lacunas pela profícua fonte de normatividade.

A constituição do novo Código Civil de 2002, por ocasião da criação da comissão que reformularia o Código de 1916/1917, em 1967, trouxe no projeto original a presença de cláusulas abertas que, muito embora lá presentes, ainda assim, quando da redação final, sofreram inúmeras emendas em razão da nova Constituição Federal, que procuravam alinhar o Código em construção às novas diretrizes e aos vetores sociais emergente da Carta de 1988 (DINIZ, 2019).

O Código Civil passa a contar com uma nova dimensão: a responsabilidade social. Não se fala mais apenas em responsabilidade civil objetiva e subjetiva, mas sim de responsabilidade social e função social dos institutos do direito privado, de modo que essa carga valorada é maximizada pela constituinte, porém já presente no contexto do novo ordenamento civilista, de modo que vai afirmar Grau (2014, p. 35),

Ontem, os códigos; hoje, as Constituições. A revanche da Grécia sobre Roma, tal como se deu, noutro plano, na evolução do direito de propriedade, antes justificado pela origem, agora legitimado pelos fins: a propriedade que não cumpre sua função social não merece proteção jurídica qualquer.

Os elementos presentes no Código Civil demonstram que o novo ordenamento já nasceu com as diretrizes constitucionais de responsabilidade social. Dessa forma, como ensina Diniz (2019), o princípio da socialidade demonstra o interesse coletivo que deve prevalecer sobre o individual, refletindo em maior grau a função social do contrato e da propriedade. O princípio da eticidade igualmente contempla o princípio constitucional da probidade, que na Constituição é exigido apenas no trato da coisa pública, e também traduz o princípio da dignidade humana, segundo o qual, numa ética kantiana, o "homem é composto por valores que se elevam a máxima de respeito pelo semelhante" (TARTUCE, 2019, p. 91).

A questão que toca é saber que, se tudo que é da vida, por regra, é regulado pelo direito civil, estão certas as lições de "Gianturco, que grande parte da questão social reside no campo do Direito Privado” (REALE, 2002, p. 358), de modo que as contradições e tensões sociais serão refletidas no âmbito das relações interpartes, porém tendo a legislação especial sido preparada, como verificado, para lidar com essa nova realidade. 
Realidade em que os elementos da vida privada e da vida pública não possuem mais separação unívoca.

\section{A resposta adequada da Constituição}

Diante dessas ponderações, verifica-se a impossibilidade de dissociação do direito civil das normas definidoras de direito público, como as garantias estabelecidas na Constituição, devendo haver um consenso possível dentro do ordenamento. Por esse motivo, toda digressão teórica inicial leva a considerar a possibilidade de o intérprete autêntico (KELSEN, 2006) dar a correta aplicação aos direitos fundamentais na relação entre os particulares.

A corrente que se filia pela aplicação mediata por meio da atividade legislativa alegando ilegitimidade do magistrado esquece que "o legislador, ao criar uma norma jurídica geral, generaliza, estabelecendo um tipo legal que, em decorrência disso, está separado da realidade imediata da vida que lhe deu origem” (DINIZ, 2005, p. 302), portanto sendo incompatível com a natureza dos direitos fundamentais o alto grau de abstração que é da estrutura de todas as produções legislativas.

Devendo, por isso, a definição do sentido e o alcance dos direitos fundamentais serem estabelecidos mediante a atividade hermenêutica que confira sentido às suas normas, em conformidade com os fins perquiridos pelo ordenamento. É no caso concreto que se satisfaz o direito, porém nos limites gerais estabelecidos no próprio regramento jurídico vigente, pois assim os critérios não são definidos pelo juiz, uma vez que "ele empresta as pautas axiológicas consagradas na ordem jurídica” (DINIZ, 2005, p. 304).

Embora, na solução do caso concreto, as normas definidoras de direito fundamental que servem de suporte fático a princípios constitucionais devam ser satisfeitas na maior proporção possível dentro das possibilidades fáticos jurídicas (ALEXY, 2006), isso não é regra para todo e qualquer caso envolvendo direitos fundamentais entre particulares, pois a função criadora do juiz desenvolve-se pela interpretação, integração e correção (DINIZ, 2005).

Por certo que "o direito civil, importante e tradicional ramo da ciência jurídica, não é nem raiz, nem tronco principal da árvore jurídica, mas um dos ramos em que o tronco-matriz se biparte" (CRETELLA JR., 1993, p. 208), de modo que, como verificado, sua evolução histórica e as dimensões que dotou no ordenamento pátrio não podem ser ignoradas e sopesadas por análises isoladas de institutos constitucionais. 
Na atividade hermenêutica, estará verificada a necessidade de comunicar os institutos do direito civil com as definições do texto constitucional, uma vez que o Código Civil de 2002 participa em grande parte dos diálogos sociais emergentes quando da constituinte de 1987/1988. As cláusulas gerais, que se figuram à ontognoseologia de Miguel Reale (TARTUCE, 2019), como demonstrado, são suporte interpretativo primário em que se verificam possíveis constrangimentos a direitos fundamentais.

A nova postura hermenêutica do direito civil constitucional (TARTUCE, 2019) é possível, conquanto se admita que a Constituição não quis ofuscar as normas que dela e em conformidade com ela foram criadas, de modo a sua participação ser subsidiária, quando esgotadas as possibilidades prestacionais de soluções efetivas dentro do ordenamento próprio em que se deu o conflito.

\section{Conclusões}

Verificado que não prospera no novo plano constitucional a leitura isolada dos institutos provenientes da legislação infraconstitucional, foi possível concluir que há um ponto de encontro de todos os ramos do direito com sua responsabilidade esposada na Constituição. Nessa linha, o direito civil, ramo do direito privado, alinhou-se às disposições da nova Carta adotando as cláusulas gerais em sua constituição.

Porém, ainda assim, verificou-se que a realidade dos direitos fundamentais não comporta reducionismos, quer na história e categorização de sua evolução, quer na estrutura de suas definições, não sendo possível limitar, por isso, sua eficácia pela simples existência de legislação especial “suficiente”. Por isso, é necessária uma nova postura hermenêutica.

Postura essa que pode ser considerada a adotada pelos adeptos do direito civil constitucional, porém que se observe a necessidade de não esgotar os sentidos das normas jurídicas já existentes, uma vez que todas elas devem ter e têm vida útil ao ordenamento. Sendo assim, a este sentir, possível que haja eficácia horizontal e a irradiação dos princípios constitucionais sobre os casos concretos nas relações particulares após esgotadas as possibilidades jurídicas do ordenamento em que se deu o conflito, sendo esse o ordenamento civil. 


\section{REFERÊNCIAS}

ALEXY, R. Teoria dos direitos fundamentais. 2. ed. São Paulo: Malheiros Editores, 2006.

ÁVILA, H. Teoria dos princípios: da definição à aplicação dos princípios. 17. ed. São Paulo: Malheiros Editores, 2016.

BARROSO, L. R. Curso de direito constitucional contemporâneo. 5. ed. São Paulo: Saraiva, 2015.

BOBBIO, N. Teoria do ordenamento jurídico. 2. ed. São Paulo: Edipro, 2014.

BRASIL. Supremo Tribunal Federal. Disponível em: http://stf.jus.br/portal/jurisprudencia/pesquisarJurisprudencia.asp. Acesso em: 3 maio 2020.

CANOTILHO, J. J. G. In: MORAES, A. de. Direito constitucional. 35. ed. São Paulo: Atlas, 2019.

CANOTILHO, J.J. G.; MOREIRA, V.Constituição da república portuguesa anotada. 3. ed. Coimbra: Coimbra, 1993.

CRETELLA JR., J. Curso de filosofia do direito. 4. ed. Rio de Janeiro: Forense, 1993.

DINIZ, M. H. Compêndio de introdução à ciência do direito. 17. ed. São Paulo: Saraiva, 2005.

DINIZ, M. H. Curso de direito civil: teoria geral do direito civil. 36. ed. São Paulo: Saraiva, 2019.

GRAU, E. R. Interpretação do direito. In: BARRETO, V. de P. (coord.). Dicionário de filosofia do direito. Rio de Janeiro: Renovar; São Leopoldo: Unisinos, 2009. p. 471-475.

GRAU, E. R. Teixeira de Freitas. Revista da Faculdade de Direito da UFMG, n. 42, p. 35-57, fev. 2014. Disponível em: https://www.direito.ufmg.br/revista/index.php/revista/article/view/1248/1181. Acesso em: 3 maio 2020.

HACHEM, D. W. São os direitos sociais “direitos públicos subjetivos”? Mitos e confusões na teoria dos direitos fundamentais. Revista de Estudos Constitucionais, Hermenêtica e Teoria do Direito, v. 11, n. 3, p. 404-436, set./dez. 2019.

HESSE, K. A força normativa da Constituição. Tradução Gilmar F. Mendes. Porto Alegre: Sergio Antônio Fabris Editor, 1991.

KELSEN, H. Teoria pura do direito. 2. ed. São Paulo: Martins Fontes, 2006.

MAZZUOLI, V. de O. Curso de direitos humanos. Rio de Janeiro: Forense; São Paulo: Método, 2014.

MOLINA, A. A. Teoria dos princípios trabalhistas: a aplicação do modelo metodológico pós-positivista ao direito do trabalho. São Paulo: Atlas, 2013.

REALE, M. Lições preliminares de direito. 27. ed. São Paulo: Saraiva, 2002.

SARLET, I. W.; MARINONI, L. G.; MITIDIERO, D. Curso de direito constitucional. 6. ed. São Paulo: Saraiva, 2017.

SILVA, J. A. da. Aplicabilidade das normas constitucionais. 3. ed. São Paulo: Malheiros, 1998.

STRECK, L. L. Jurisdição constitucional. 5. ed. Rio de Janeiro: Forense, 2018.

TARTUCE. F. Direito civil: lei de introdução e parte geral. 15. ed. Rio de Janeiro: Forense, 2019. 